\title{
The effects of spinal manipulation on performance-related outcomes in healthy asymptomatic adult population: a systematic review of best evidence
}

\author{
Melissa Corso ${ }^{1 *}$ (D), Silvano A. Mior ${ }^{1}$, Sarah Batley ${ }^{1}$, Taylor Tuff ${ }^{1}$, Sophia da Silva-Oolup ${ }^{1}$, Scott Howitt ${ }^{1}$ and
} John Srbely ${ }^{1,2}$

\begin{abstract}
Introduction: The effectiveness of spinal manipulative therapy (SMT) for improving athletic performance in healthy athletes is unclear. Assessing the effect of SMT on other performance outcomes in asymptomatic populations may provide insight into the management of athletes where direct evidence may not be available. Our objective was to systematically review the literature on the effect of SMT on performance-related outcomes in asymptomatic adults.

Methods: MEDLINE, CINAHL, SPORTDiscus, and Cochrane Central Register of Controlled Trials were systematically searched from 1990 to March 23, 2018. Inclusion criteria was any study examining a performance-related outcome of SMT in asymptomatic adults. Methodological quality was assessed using the SIGN criteria. Studies with a low risk of bias were considered scientifically admissible for a best evidence synthesis. We calculated the between group mean change and $95 \%$ confidence intervals.

Results: Of 1415 articles screened, 20 studies had low risk of bias, seven were randomized crossover trials, 10 were randomized controlled trials (RCT) and three were RCT pilot trials. Four studies showed SMT had no effect on physiological parameters at rest or during exercise. There was no effect of SMT on scapular kinematics or transversus abdominus thickness. Three studies identified changes in muscle activation of the upper or lower limb, compared to two that did not. Five studies showed changes in range of motion (ROM). One study showed an increase lumbar proprioception and two identified changes in baropodometric variables after SMT. Sport-specific studies show no effect of SMT except for a small increase in basketball free-throw accuracy.

Conclusion: The preponderance of evidence suggests that SMT in comparison to sham or other interventions does not enhance performance-based outcomes in asymptomatic adult population. All studies are exploratory with immediate effects. In the few studies suggesting a positive immediate effect, the importance of such change is uncertain. Further high-quality performance specific studies are required to confirm these preliminary findings.
\end{abstract}

Keywords: Spinal manipulation, Athlete, Asymptomatic, Healthy, Performance, Sport

\footnotetext{
* Correspondence: mcorso@cmcc.ca

${ }^{1}$ Canadian Memorial Chiropractic College, 6100 Leslie Street, North York, ON

$\mathrm{M} 2 \mathrm{H}$ 3J1, Canada

Full list of author information is available at the end of the article
}

(c) The Author(s). 2019 Open Access This article is distributed under the terms of the Creative Commons Attribution 4.0 International License (http://creativecommons.org/licenses/by/4.0/), which permits unrestricted use, distribution, and reproduction in any medium, provided you give appropriate credit to the original author(s) and the source, provide a link to the Creative Commons license, and indicate if changes were made. The Creative Commons Public Domain Dedication waiver (http://creativecommons.org/publicdomain/zero/1.0/) applies to the data made available in this article, unless otherwise stated. 


\section{Introduction}

Chiropractors are an integral part of injury management for the athlete. Fellows of the Royal College of Chiropractic Sports Sciences (Canada) (RCCSS(C)) report that up to $25 \%$ of their practice is comprised of athletes and 49.5\% of Australian chiropractors report 'often' treating athletes [1,2]. In addition, $29 \%$ of intercollegiate athletes use chiropractic treatment [3] and 31\% of NFL teams employ chiropractors as an official part of their staff [4]. SMT is a well-documented intervention, typically provided by a chiropractor, for spinal pain and musculoskeletal injuries [1, 3, 5-7]. However, $84 \%$ of $\operatorname{RCCSS}(\mathrm{C})$ fellows also reported witnessing performance enhancements in asymptomatic athletes immediately after SMT and/or adjunctive therapy [1]. Minor enhancements in performance can have significant implications to an athlete. For example, the difference between first and third place in the 100-m sprint during the 2016 Rio Olympics was only 100 milliseconds [8]. Some athletes insist on being treated before competition to optimize performance despite having no musculoskeletal complaints, and $94 \%$ of those athletes utilizing chiropractic care at the 2013 World Games reported immediate improvements [9].

Despite the anecdotal evidence that SMT improves performance, the literature on the effect of SMT on athletic performance and/or performance-related outcomes is equivocal and lacks methodological rigor. Miners [10] conducted a narrative review and reported that, although many theoretical frameworks have been proposed, insufficient evidence exists to support the claim that chiropractic treatment directly and significantly improves performance in athletes. The theoretical frameworks identified by Miners [10] include the improvements of abnormal spinal mechanics, muscular coordination, activation and reaction time, and motor training [10]. In 2017, Cerqueira et al. [11] and Botelho et al. [12] conducted similar but separate systematic reviews assessing the effect of SMT on performance in athletes, with the Botelho et al. review including three additional studies. Cerqueira et al. [11] concluded that current evidence is insufficient to determine the use or non-use of SMT to improve athletic or sport-specific performance [11]. In contrast, while Botelho et al. [12] agreed that while the evidence is weak, most studies showed an improvement in athletic performance with SMT [12]. Both authors recommend that this topic requires greater methodological rigor and further investigation [11, 12].

All three of these reviews were specific to athletic populations and sport-specific outcomes. Limitations of these reviews include lack of clear inclusion criteria for studies and inclusion of studies of low methodological quality. Furthermore, these reviews did not include studies measuring the effect of SMT on performance outcomes among asymptomatic populations that may be relevant to athletic performance. Such performance effects might also be of interest to athletes who are seeking performance benefits, as they would be receiving SMT in the absence of pain or injury, similar to an asymptomatic subject. Both of these populations, whether an asymptomatic healthy subject or an athlete seeking performance enhancement would be expected to fundamentally respond in the same direction when stimulated by an external force such as SMT [13, 14]. However, the application of this response would differ between the populations, for example, a sprint in the athlete or walking ability in a non-athlete. We suggest that the response to SMT in either population would be similar, while the context of its application changes based on the tasks required of the subject. Thus, our systematic review includes studies investigating healthy asymptomatic adult populations for related measurable changes that may directly or indirectly affect performance and/or function rather than to manage specific injuries or neuromusculoskeletal complaints.

Our objective was to systematically review the literature on the effect of SMT compared to other interventions, placebo/sham intervention, and no intervention on performance-related outcomes (ie, physiological, biomechanical, and sport-specific outcomes) in healthy asymptomatic individuals.

\section{Methods \\ Registration}

We registered this review protocol with the International Prospective Register of Systematic Reviews (PROSPERO) on May 22, 2017 (CRD42017067090).

\section{Search strategy}

We developed our search strategy in consultation with a health sciences librarian, and the strategy was reviewed by a second librarian using the Peer Review of Electronic Search Strategies (PRESS) Checklist $[15,16]$. The following electronic databases were systematically searched from January 1, 1990 to March 23, 2018: MEDLINE, CINAHL, SPORTDiscus, and Cochrane Central Register of Controlled Trials. Search terms consisted of subject headings specific to each database (e.g., MeSH in MEDLINE) and free text words relevant to our PICO components (Additional file 1: Appendix I). In addition, we hand searched the reference lists of relevant studies for any relevant citations that may not have been retrieved by our search.

\section{Selection of studies}

Studies were included if they met the following criteria: 1) published in English language and in a peer-reviewed journal; 2) study designs including: randomized 
controlled trials (RCT), cohort, and pilot studies; 3) study population including asymptomatic adults $(>18$ years old); 4) intervention consisted of spinal and pelvic SMT (high velocity, low amplitude) compared with placebo/sham, no intervention, or an alternative intervention; and 5) outcome measures must include at least one performance parameter such as range of motion, strength, power, motor control, agility, balance, or speed.

Studies fulfilling any of the following criteria were excluded: 1) publication types including: guidelines, letters, editorials, commentaries, unpublished manuscripts, dissertations, government reports, books and book chapters, conference proceedings, meeting abstracts, lectures and addresses, consensus development statements, guideline statements; 2) study designs including: feasibility and cross-sectional studies, case reports, case series, qualitative studies, non-systematic and systematic reviews, clinical practice guidelines, studies not reporting on methodology; and 3) cadaveric or animal studies. We used the National Institute for Health Research (NIHR) definitions to distinguish pilot and feasibility studies; pilot studies are smaller versions of the main study whereas a feasibility study are used to estimate important parameters that are needed to design the main study [17].

\section{Definitions}

SMT was defined as a controlled, high-velocity, low amplitude mechanical intervention leading to the deformation of the spine and surrounding soft tissues [18]. Athletic performance, defined by the National Strength and Conditioning Association, is the ability to respond effectively to various physical challenges [19]. Examples of features related to athletic performance include, but not limited to: strength, power, endurance, agility and speed [19]. Biomechanics is defined as the study of biological systems, particularly of their structure and function, and specifically being concerned with the effect these forces have on motion of bodies [20]. Physiology is defined as the study of the functioning of living organisms (animal or plant) and of their constituent tissues or cells [21]. Asymptomatic is defined as a study population presenting with no current symptoms of disease [22].

\section{Screening of titles and abstracts}

All citations identified by the search strategy were exported into EndNote X6 for reference management and tracking of the screening process. We used a two-phase approach to screening with pairs of independent reviewers screening each citation and article (MC with SM, TT, SH, JS). In the first phase, titles and abstracts were screened for relevant, irrelevant and possibly relevant citations. Possibly relevant citations from the first phase were reviewed in the second phase using full text screening. Any disagreement was resolved by discussion between the paired reviewers to reach consensus. If consensus was not reached, a third reviewer independently appraised the citation and discussed with the other two reviewers to reach consensus.

\section{Critical appraisal}

All relevant studies were critically appraised for risk of bias independently by rotating pairs of reviewers (MC with SM, SB, TT, SD, SH, JS). Risk of bias was assessed using the Scottish Intercollegiate Guidelines Network (SIGN) criteria for randomized controlled trials and cohort studies [23, 24]. The SIGN criteria were used to evaluate the nature and impact of selection and information bias, and potential confounding on the results of the study. A quantitative score or cut-point was not used to determine internal validity. The SIGN criteria guided reviewers in their assessment of the overall internal validity of the study, and studies scored as "accepted" were included in the final analysis [25].

We critically assessed the following methodological aspects (where appropriate or applicable) in each study: clarity of research question; randomization method; concealment of the treatment allocation; blinding of treatment and outcomes; similarity of baseline characteristics between/among treatment arms; co-intervention contamination; validity and reliably of outcome measures; follow-up rates; analysis according to intention-to- treat principles; and comparability of results across study sites.

Following critical appraisal, studies with a low risk of bias as determined and agreed upon by reviewing pairs were considered scientifically admissible for a best evidence synthesis [26]. We did not exclude studies based on a minimum number of participants as suggested by others [6]; rather the precision of the study's findings was considered when interpreting the results and conclusion by assessing the between group mean change and $95 \%$ confidence intervals $(\mathrm{CI})$ where possible. We did not conduct a sensitivity analysis as this was considered beyond the scope of this review.

\section{Synthesis}

One reviewer (MC) extracted data from scientifically admissible studies to build evidence tables (Table 1). Data extraction was checked by a second reviewer (SM). Evidence tables outlined the calculated between group mean change and 95\% CI where applicable, best evidence on each topic, identified consistencies and inconsistencies in the evidence and were used to create summary statements describing the body of evidence [26]. Evidence was stratified based on outcome measures into one of three categories: physiological, biomechanical and sport-specific outcomes. 


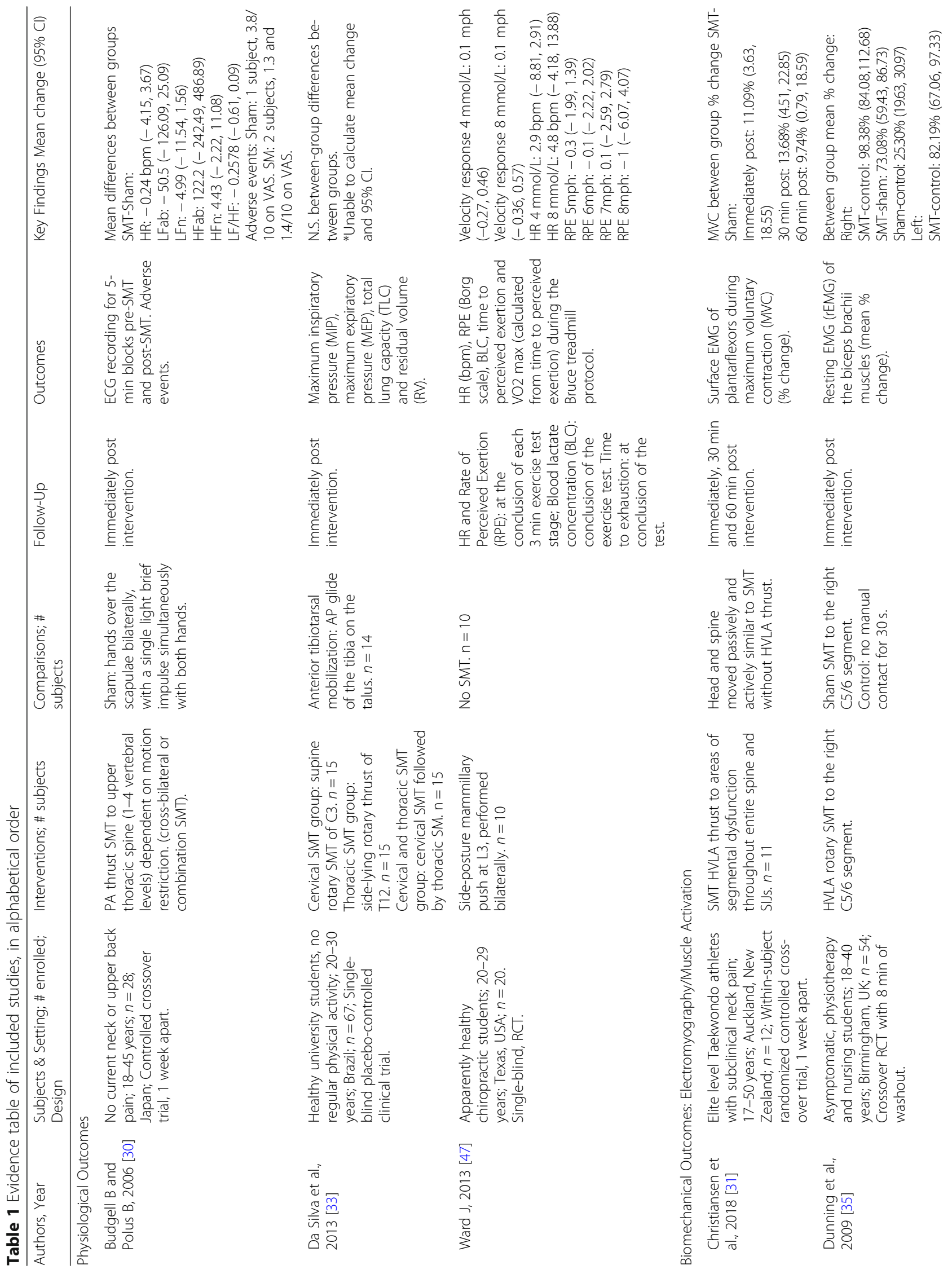




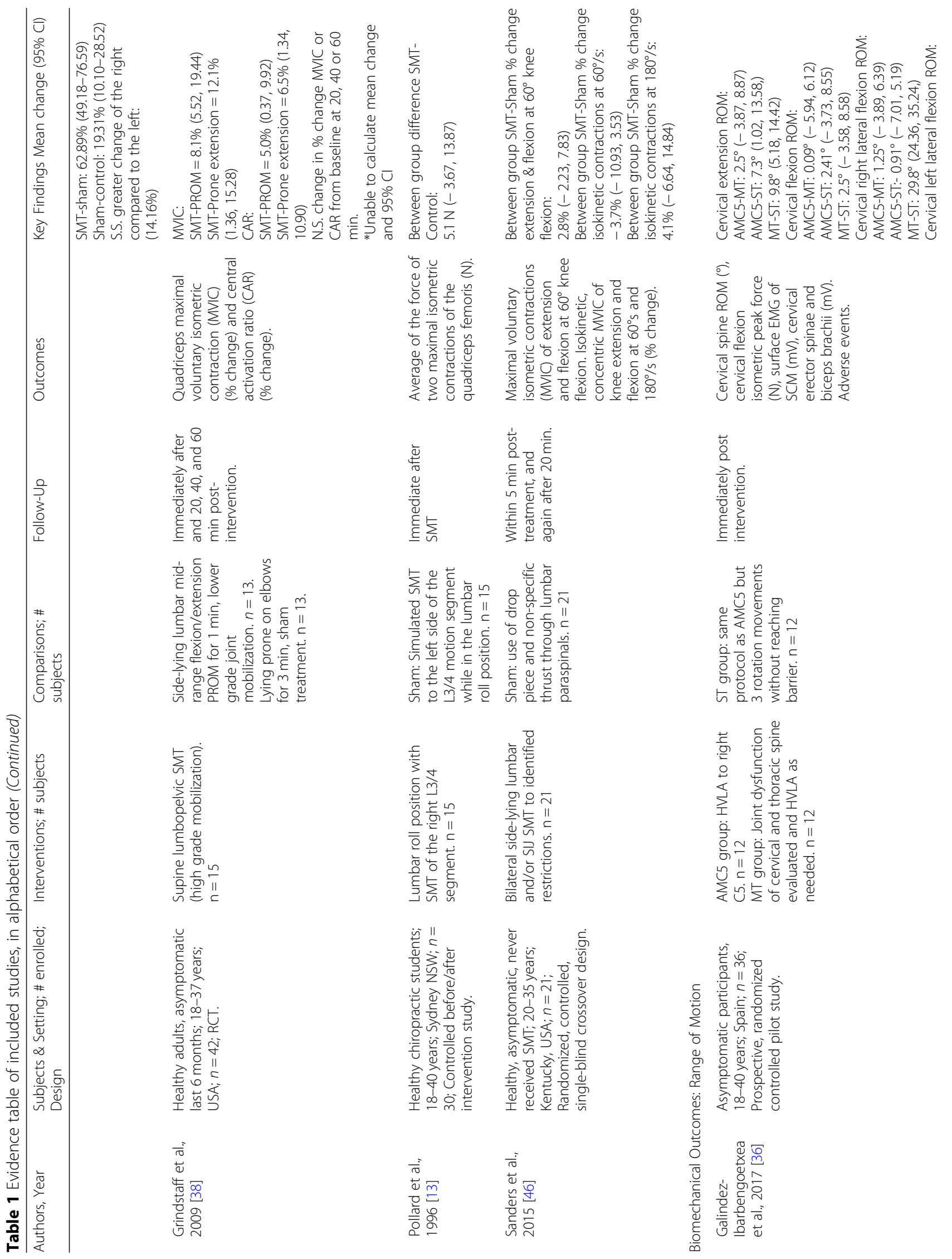




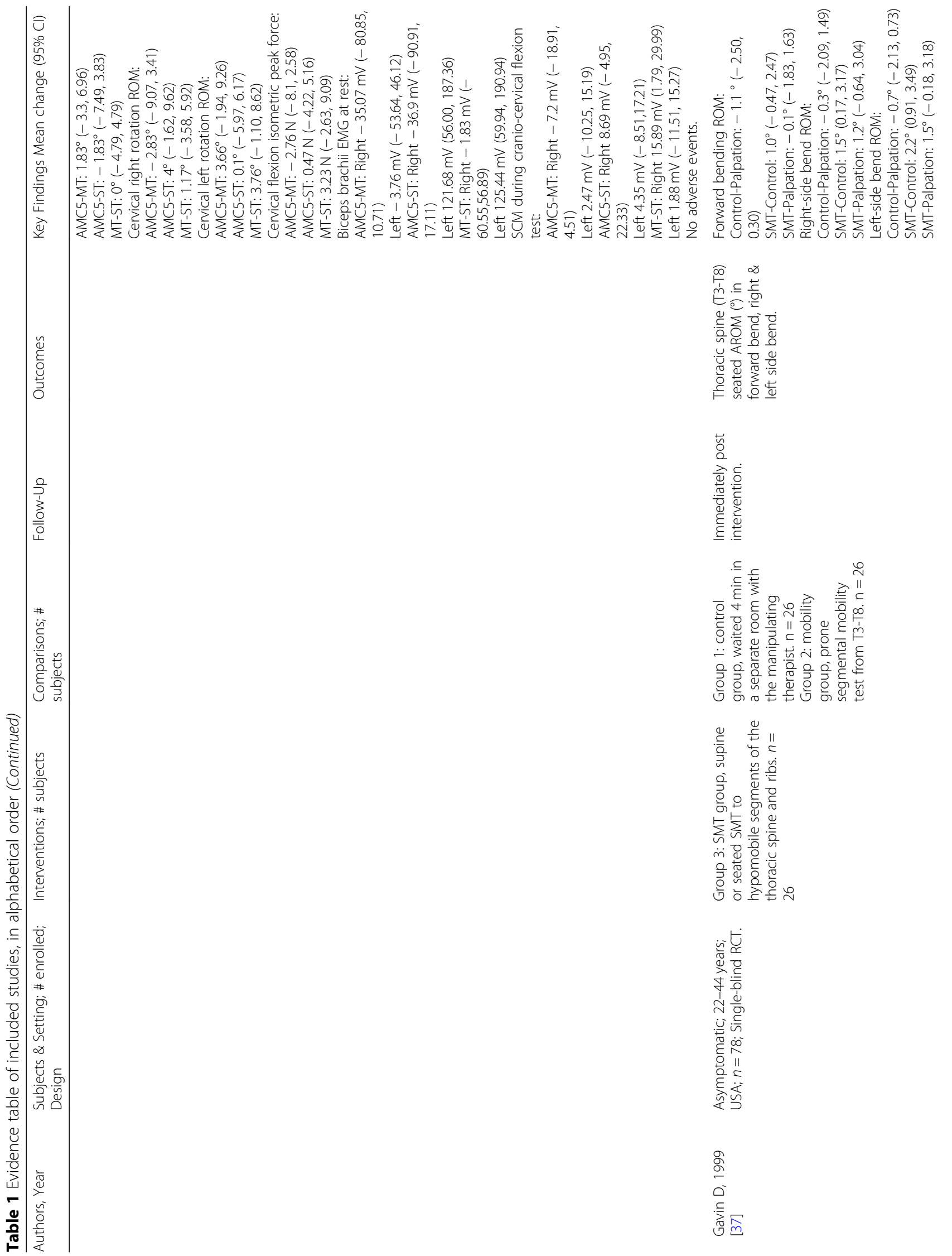




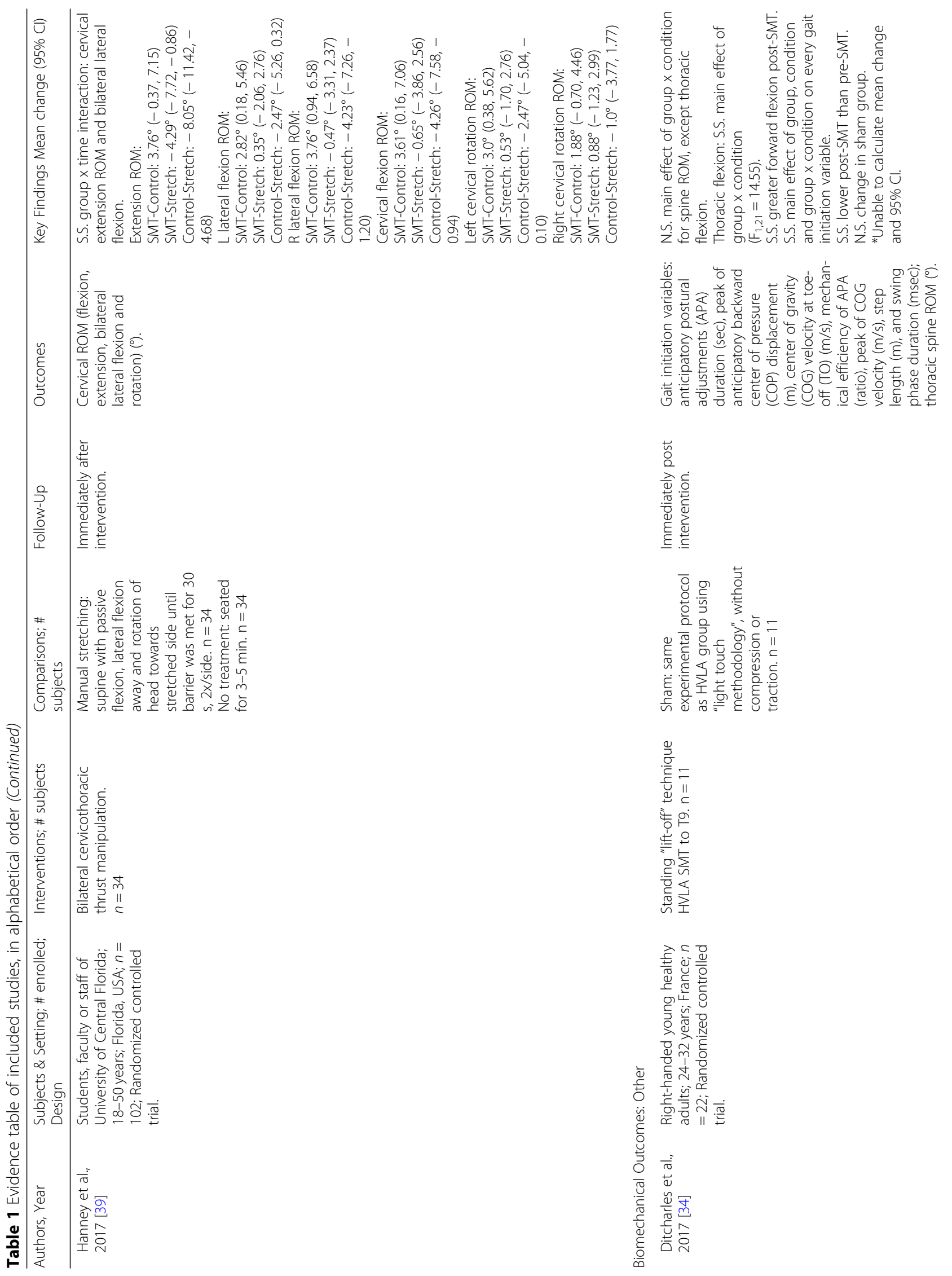




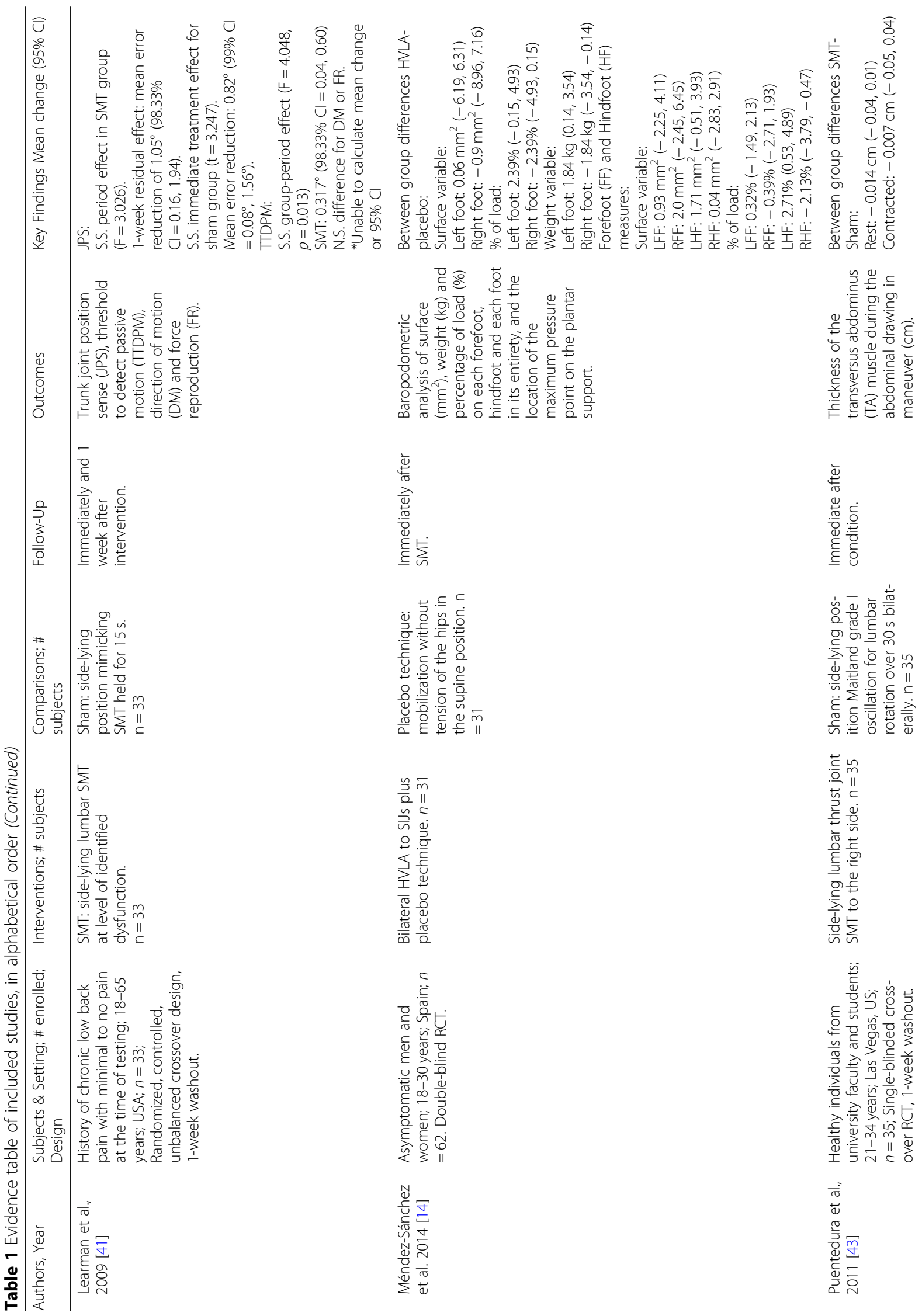




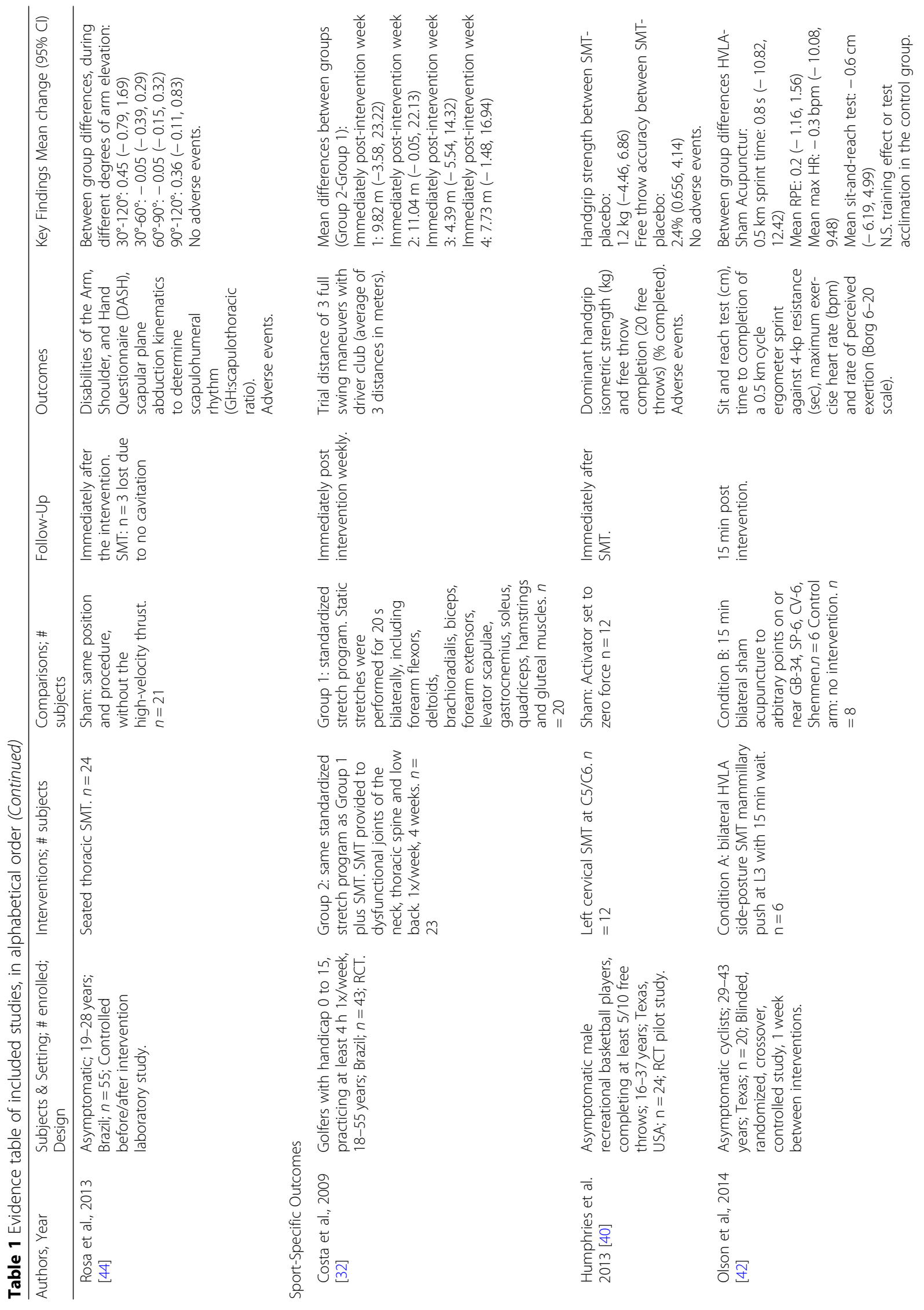




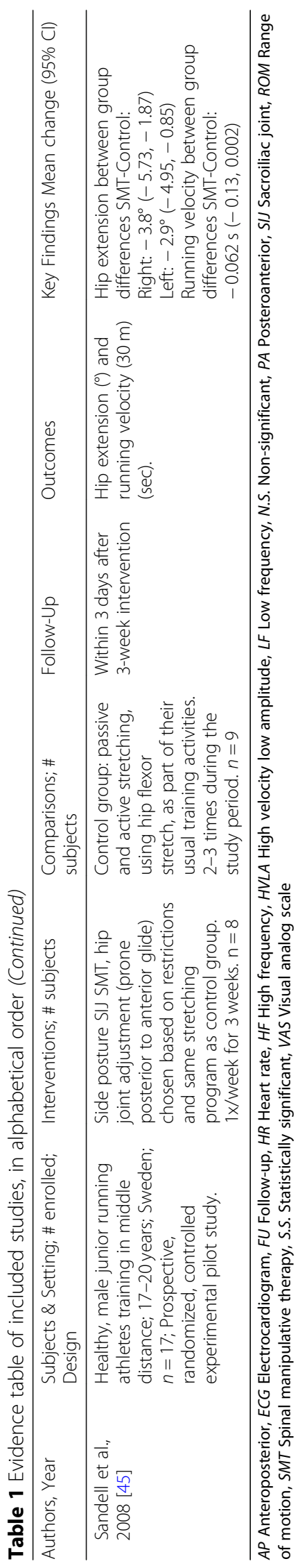




\section{Statistical analyses}

We computed the inter-rater reliability for each pair of phase 1 and phase 2 screening using the Cohen's kappa coefficient (к) $[27,28]$. Where possible, the $95 \%$ confidence interval $(\mathrm{CI})$ for the difference in mean change was calculated. We deemed a $p$-value of $<0.05$ to be statistically significant.

\section{Reporting}

This systematic review was organized and reported based on the Preferred Reporting Items for Systematic Review and Meta-Analyses (PRISMA) statement [29].

\section{Results}

\section{Study selection}

Our search retrieved 1415 articles, of which 52 articles were eligible for critical analysis after applying inclusion and exclusion criteria (Fig. 1). Articles were excluded after phase 2 screening due to ineligible study design, interventions not consistent with our definition of SMT, research questions addressing the effect of SMT on specific conditions and pain or the effect on SMT in asymptomatic adults with outcome measures not deemed to be relevant to performance (i.e. neurophysiological parameters, such as $\mathrm{H}$-wave and $\mathrm{M}$-wave).The mean interrater agreement for phase 1 was $\mathrm{K}=0.934$ (range: $0.88-0.97$ ) and phase 2 was $K=0.5$ (range $0.17-0.73$ ). Disagreements were primarily related to outcome measures of screened studies due to the broad definition of performance-related outcomes. Disagreements were resolved with discussion between reviewing pairs. A total of 20 articles were deemed to have a low risk of bias and were included in our systematic review; articles deemed to have a high risk of bias were not included.

\section{Risk of bias within studies}

All studies were appraised using the SIGN criteria for $\mathrm{RCT}$, as none were cohort studies. Mean reliability of appraisal was $\mathrm{K}=0.39$ (range: $-0.88-1.0$ ). We critically appraised 52 studies, of these 32 were deemed to have a high risk of bias (Appendix 2) [see Additional file 2], and were not included in this review. Methodological weakness of the studies with a high risk of bias included lack of clear research question $(n=4)$, randomization $(n=16)$ or disclosure of concealment methodology $(n=29)$, lack of investigator or subject blinding $(n=25)$, no baseline

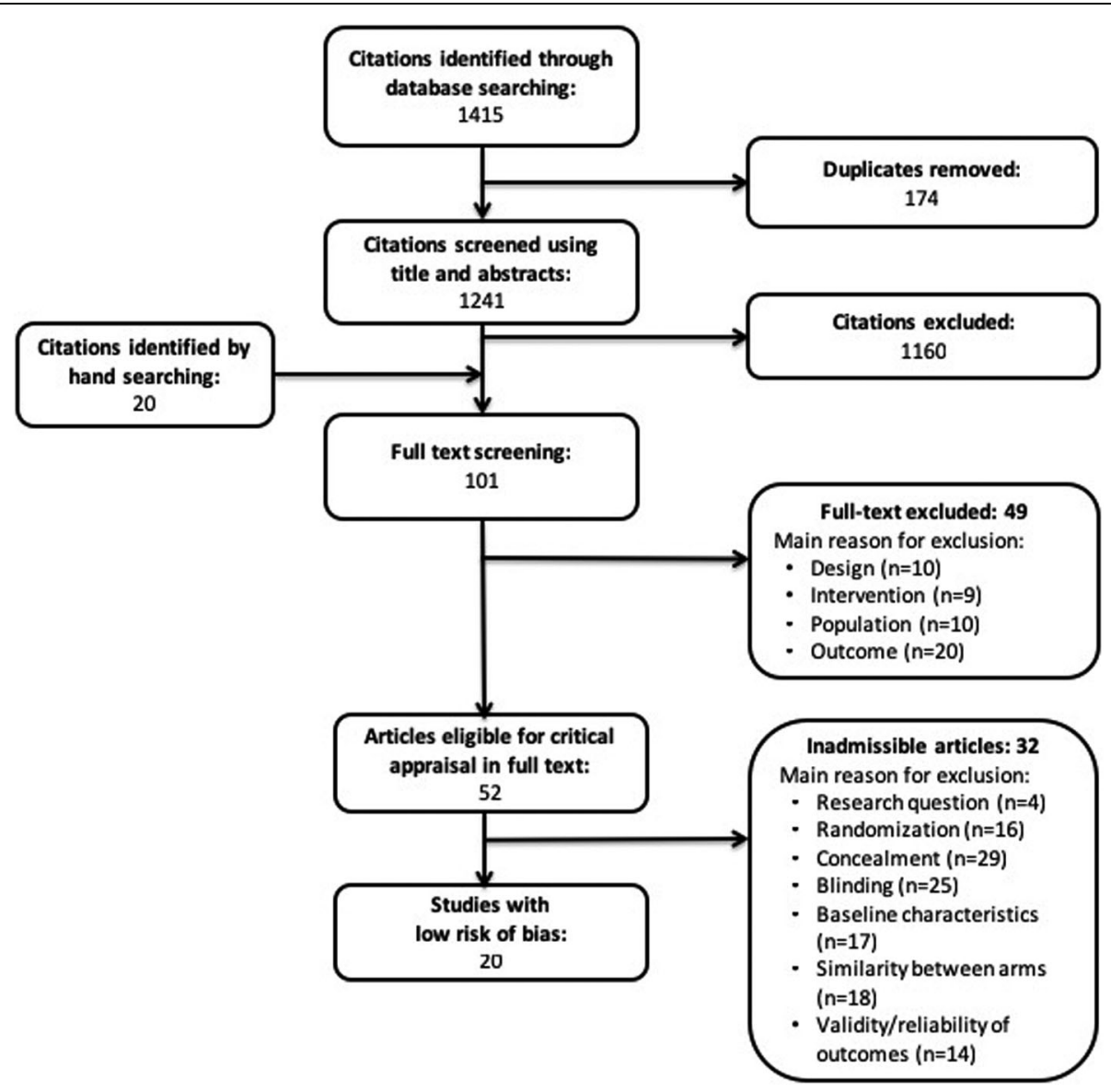

Fig. 1 Flow diagram of study selection process 
characteristics of participants $(n=17)$, differences between groups at baseline $(n=17)$ and questionable validity and reliability of the outcome measures $(n=14)$ (Tables 2 and 3).

The 20 articles accepted [13, 14, 30-47] for this review were deemed to have a low risk of bias. Methodological weaknesses in these studies included no disclosure of concealment methodology $(n=12)$, lack of participant or investigator blinding $(n=7)$, similarities at baseline $(n=1)$ (Table 4). We calculated between group mean change and $95 \% \mathrm{CI}$ for all but four studies [33, 34, 38, 41].

\section{Study characteristics}

We included 20 articles with a low risk of bias, of which seven were randomized controlled crossover studies [30, $31,35,41-43,46], 10$ were randomized controlled trials (RCT) $[13,14,32-34,37-39,44,47]$ and three were RCT pilot studies [36, 40, 45].

Location, type and direction of SMT, and outcome measures (physiological, biomechanical or sport-specific) varied in each study (Table 1). Studies included had various theoretical frameworks for the location and direction of SMT; including neurophysiological, spinal restriction or dysfunction, and theoretical associations of segment dysfunction with specific outcomes. Four studies reported on adverse events [30, 36, 40, 44]. Four studies reported on physiological outcomes [30, 33, 42, 47], 16 studies reported on biomechanical outcomes [13, $14,31,34-46]$, three of which also reported on sport-specific outcomes [40, 42, 45], and one additional study reported on performance variables for specific sports [32, 42].

\section{Physiological outcomes}

Four studies investigated the effect of SMT on physiological outcomes in asymptomatic subjects $[30,33,42$, 47] (Table 1). There was no significant effect of thoracic SMT on resting heart rate (HR) or HR variability and no effect of lumbar SMT on exercising HR [30, 42, 47]. In addition, Ward [47] showed that mid-lumbar SMT had no significant effect on other exercise science measures, including rate of perceived exertion (RPE) during the Bruce treadmill test, calculated $\mathrm{VO}_{2} \max$, or blood lactate concentration [47]. This was further supported by Olson et al. [42] where they reported no significant effect of bilateral mid-lumbar SMT on RPE during a $500 \mathrm{~m}$ cycle ergometer sprint [42]. In the fourth study, Da Silva et al. [33] examined the effect of cervical, thoracic, combination SMT (cervical and thoracic) and extremity mobilization (placebo group) on

Table 2 Risk of bias table based on Scottish Intercollegiate Guidelines Network (SIGN) Criteria for high risk of bias studies; randomized controlled trials

\begin{tabular}{|c|c|c|c|c|c|c|c|c|c|c|c|}
\hline Author, Year & $\begin{array}{l}\text { Research } \\
\text { Question }\end{array}$ & Randomization & Concealment & Blinding & $\begin{array}{l}\text { Similarity } \\
\text { at baseline }\end{array}$ & $\begin{array}{l}\text { Similarity } \\
\text { between } \\
\text { arms }\end{array}$ & $\begin{array}{l}\text { Outcome } \\
\text { measures }\end{array}$ & $\begin{array}{l}\text { Percent } \\
\text { drop-out }\end{array}$ & $\begin{array}{l}\text { Intention } \\
\text { to treat }\end{array}$ & $\begin{array}{l}\text { Results } \\
\text { between } \\
\text { sites }\end{array}$ & $\begin{array}{l}\text { Level of } \\
\text { evidence }\end{array}$ \\
\hline Botelho et al., 2012 & $\mathrm{Y}$ & $\mathrm{Y}$ & CS & $\mathrm{N}$ & $\mathrm{N}$ & $\mathrm{N}$ & $Y$ & $0 \%$ & NA & NA & $1-$ \\
\hline Cardinale et al., 2015 & Y & Y & N & CS & Y & Y & CS & $0 \%$ & NA & NA & $1-$ \\
\hline Enebo et al., 2003 & Y & Y & CS & N & CS & CS & CS & $0 \%$ & CS & NA & $1-$ \\
\hline Engel et al. 2007 & Y & Y & Y & CS & N & $\mathrm{N}$ & CS & $20 \%$ & $N$ & NA & $1-$ \\
\hline Fox et al., 2006 & Y & Y & CS & N & Y & Y & CS & CS & CS & NA & $1-$ \\
\hline Miller et al., 2000 & Y & Y & $\mathrm{N}$ & N & Y & Y & CS & CS & Y & NA & $1-$ \\
\hline Nansel et al., 1992 & Y & Y & CS & N & CS & CS & Y & $0 \%$ & Y & NA & $1-$ \\
\hline Nansel et al., 1993 & Y & Y & CS & Y & CS & Y & CS & $0 \%$ & Y & NA & $1-$ \\
\hline Palmgren et al., 2009 & Y & Y & Y & N & CS & Y & Y & $0 \%$ & Y & NA & $1-$ \\
\hline Passmore et al., 2010 & Y & Y & CS & Y & CS & CS & Y & $0 \%$ & Y & NA & $1-$ \\
\hline Pollard et al., 1998 & Y & Y & CS & CS & CS & CS & CS & CS & CS & NA & $1-$ \\
\hline $\begin{array}{l}\text { Schwartzbauer } \\
\text { et al., } 1997\end{array}$ & CS & Y & N & N & CS & CS & CS & $25 \%$ & Y & NA & $1-$ \\
\hline Shrier et al., 2006 & Y & Y & CS & CS & Y & Y & Y & $17.6 \%$ & Y & NA & $1-$ \\
\hline $\begin{array}{l}\text { Stamos-Papastamos } \\
\text { et al., } 2011\end{array}$ & Y & Y & CS & N & Y & Y & Y & CS & Y & NA & $1-$ \\
\hline Straub et al., 2001 & Y & Y & CS & CS & CS & CS & Y & $0 \%$ & Y & NA & $1-$ \\
\hline Ward et al., 2012 & $\mathrm{~N}$ & Y & $\mathrm{N}$ & N & CS & CS & CS & $5 \%$ & NA & NA & $1-$ \\
\hline Ward et al., 2013 & Y & Y & Y & N & N & $\mathrm{N}$ & Y & $0 \%$ & CS & NA & $1-$ \\
\hline Ward et al., 2014 & Y & Y & $\mathrm{N}$ & N & Y & Y & $N$ & $0 \%$ & Y & NA & $1-$ \\
\hline
\end{tabular}

Y Yes, N No, CS Can't say, NA Not applicable 
Table 3 Risk of bias table based on Scottish Intercollegiate Guidelines Network (SIGN) Criteria for high risk of bias studies; nonrandomized trials

\begin{tabular}{|c|c|c|c|c|c|c|c|c|c|c|c|}
\hline Author, Year & $\begin{array}{l}\text { Research } \\
\text { Question }\end{array}$ & Randomization & Concealment & Blinding & $\begin{array}{l}\text { Similarity } \\
\text { at baseline }\end{array}$ & $\begin{array}{l}\text { Similarity } \\
\text { between } \\
\text { arms }\end{array}$ & $\begin{array}{l}\text { Outcome } \\
\text { measures }\end{array}$ & $\begin{array}{l}\text { Percent } \\
\text { drop-out }\end{array}$ & $\begin{array}{l}\text { Intention } \\
\text { to treat }\end{array}$ & $\begin{array}{l}\text { Results } \\
\text { between } \\
\text { sites }\end{array}$ & $\begin{array}{l}\text { Level of } \\
\text { evidence }\end{array}$ \\
\hline Barbosa et al., 2014 & Y & $\mathrm{N}$ & NA & NA & CS & CS & Y & $0 \%$ & Y & NA & $1-$ \\
\hline Bonci et al., 1990 & N & $N$ & NA & NA & Y & $N$ & CS & $0 \%$ & Y & NA & $1-$ \\
\hline Deutschmann et al., 2011 & Y & $\mathrm{N}$ & NA & NA & Y & $\mathrm{N}$ & Y & $0 \%$ & Y & NA & $1-$ \\
\hline Lauro et al., 1991 & Y & CS & NA & NA & $\mathrm{N}$ & CS & CS & CS & Y & NA & $1-$ \\
\hline Nansel et al., 1991 & Y & $\mathrm{N}$ & NA & NA & CS & CS & Y & $0 \%$ & Y & NA & $1-$ \\
\hline
\end{tabular}

$Y$ Yes, N No, CS Can't say, NA Not applicable

According to SIGN Criteria, if groups are not randomized, the criteria can continue to be used, but sections $1.2,1.3$, and 1.4 are not applied, corresponding to randomization, concealment and blinding

maximum inspiratory pressure (MIP), maximum expiratory pressure (MEP) and total lung capacity (TLC) in healthy University students [33]. There were no significant between-group differences reported and we did not calculate mean change and $95 \%$ CI from this study [33].

\section{Biomechanical outcomes}

\section{Electromyographical/muscle force}

Seven studies examined the effect of SMT on muscle activation or strength of the lower limb in healthy subjects $[13,31,35,36,38,40,46]$ (Table 1). Four of these studies identified a significant change in muscle function [31,

Table 4 Risk of bias table based on Scottish Intercollegiate Guidelines Network (SIGN) Criteria for low risk of bias studies

\begin{tabular}{|c|c|c|c|c|c|c|c|c|c|c|c|}
\hline Author, Year & $\begin{array}{l}\text { Research } \\
\text { Question }\end{array}$ & Randomization & Concealment & Blinding & $\begin{array}{l}\text { Similarity } \\
\text { at baseline }\end{array}$ & $\begin{array}{l}\text { Similarity } \\
\text { between } \\
\text { arms }\end{array}$ & $\begin{array}{l}\text { Outcome } \\
\text { measures }\end{array}$ & $\begin{array}{l}\text { Percent } \\
\text { drop-out }\end{array}$ & $\begin{array}{l}\text { Intention } \\
\text { to treat }\end{array}$ & $\begin{array}{l}\text { Results } \\
\text { between } \\
\text { sites }\end{array}$ & $\begin{array}{l}\text { Level of } \\
\text { evidence }\end{array}$ \\
\hline $\begin{array}{l}\text { Budgell B and } \\
\text { Polus B, } 2006\end{array}$ & Y & Y & $\mathrm{N}$ & CS & Y & Y & Y & $10.7 \%$ & Y & NA & $1+$ \\
\hline $\begin{array}{l}\text { Christiansen } \\
\text { et al., } 2018\end{array}$ & Y & Y & CS & N & Y & Y & Y & $8 \%$ & Y & NA & $1+$ \\
\hline Costa et al., 2009 & Y & Y & CS & Y & Y & Y & Y & $0 \%$ & Y & CS & $1+$ \\
\hline Da Silva et al., 2013 & Y & Y & CS & Y & $\mathrm{N}$ & Y & Y & $6 \%$ & Y & NA & $1+$ \\
\hline Ditcharles et al., 2017 & Y & Y & Y & $\mathrm{N}$ & Y & Y & Y & $0 \%$ & Y & NA & $1+$ \\
\hline Dunning et al., 2009 & Y & Y & CS & $\mathrm{N}$ & Y & Y & Y & $0 \%$ & NA & NA & $1+$ \\
\hline $\begin{array}{l}\text { Galindez- } \\
\text { Ibarbengoetxea } \\
\text { et al., } 2017\end{array}$ & Y & Y & Y & Y & Y & Y & Y & $0 \%$ & Y & NA & $1+$ \\
\hline Gavin D, 1999 & Y & Y & CS & Y & Y & Y & Y & $0 \%$ & Y & NA & $1+$ \\
\hline Grindstaff et al., 2009 & Y & Y & CS & CS & Y & Y & Y & $0 \%$ & Y & NA & $1+$ \\
\hline Hanney et al., 2017 & Y & Y & Y & $\mathrm{N}$ & Y & Y & Y & $0 \%$ & Y & NA & $1+$ \\
\hline $\begin{array}{l}\text { Humphries } \\
\text { et al. } 2013\end{array}$ & Y & Y & CS & Y & Y & Y & Y & $0 \%$ & Y & NA & $1++$ \\
\hline Learman et al., 2009 & Y & Y & CS & $\mathrm{N}$ & Y & Y & CS & $0 \%$ & Y & NA & $1+$ \\
\hline $\begin{array}{l}\text { Mendez-Sanchez } \\
\text { et al. } 2014\end{array}$ & Y & Y & CS & Y & Y & Y & Y & $0 \%$ & Y & NA & $1++$ \\
\hline Olson et al., 2014 & Y & Y & Y & Y & Y & Y & Y & $0 \%$ & Y & NA & $1++$ \\
\hline Pollard et al., 1996 & Y & Y & CS & Y & Y & Y & Y & $0 \%$ & Y & NA & $1+$ \\
\hline $\begin{array}{l}\text { Puentedura } \\
\text { et al., } 2011\end{array}$ & Y & Y & Y & Y & CS & Y & Y & $0 \%$ & Y & NA & $1+$ \\
\hline Rosa et al., 2013 & Y & Y & Y & Y & Y & Y & Y & $14.2 \%$ & Y & NA & $1+$ \\
\hline Sandell et al., 2008 & Y & Y & Y & Y & CS & Y & Y & $0 \%$ & Y & NA & $1+$ \\
\hline Sanders et al., 2015 & Y & Y & Y & Y & Y & Y & Y & $0 \%$ & Y & NA & $1++$ \\
\hline Ward J, 2013 & Y & Y & $N$ & Y & Y & Y & Y & $0 \%$ & Y & NA & $1+$ \\
\hline
\end{tabular}

Y Yes, N No, CS Can't say, NA Not applicable 
$35,36,38]$. SMT based on identified joint dysfunction of the cervical, thoracic and lumbar spine, and pelvis was shown to increase soleus plantar flexion maximum voluntary contraction (MVC) compared to a control group of similar active and passive range of motion (ROM) [31]. These increases were statistically significant immediately and $30 \mathrm{~min}$ after SMT but not $60 \mathrm{~min}$ after [31]. In a study comparing lumbopelvic SMT to passive ROM and passive prone extension interventions, quadriceps MVC and activation immediately significantly increased from baseline [38]. These differences were transient and were not statistically significant between the three groups at later time points (i.e. 20, 40 or $60 \mathrm{~min}$ ) [38]. We did not calculate mean change and $95 \%$ CI from this study. In contrast, two studies reported no significant effect of SMT; one showed no significant change in quadriceps MVC after L3-4 SMT compared to sham manipulation [13] and the second showed no significant change in knee extension or flexion muscle activation or peak torques at $60^{\circ} / \mathrm{sec}$ and $180^{\circ} / \mathrm{sec}$ during isokinetic concentric testing compared to a non-specific drop piece procedure [46].

Three studies investigated the effect of cervical SMT on muscle force or function immediately post intervention $[35,36,40]$ (Table 1). The first study compared cervical SMT based on identified joint dysfunction, to SMT to the right $\mathrm{C} 5$ segment, and passive range of motion (ROM) groups [36]. There was no significant difference between groups for peak cervical flexion isometric contraction. There was no significant difference in resting biceps EMG except for the left biceps with SMT based on joint dysfunction or C5 segment compared to the ROM group. There was no significant difference in sternocleidomastoid (SCM) muscle activation during the cranio-cervical flexion test except for the right SCM in the manipulation by dysfunction group compared to the ROM group [36]. Humphries et al. [40] found no significant effect of left cervical C5-6 SMT on right handgrip strength compared to an Activator adjusting instrument set to zero force [40]. In contrast, Dunning et al. [35] identified that right-sided cervical SMT to C5-6 segment significantly increased bilateral biceps brachii resting EMG activity greater than sham SMT to C5-6 segment or no manual contact [35]. This effect was significantly greater on the right, compared to the left side [35].

\section{Range of motion}

Two studies identified specific ROM changes immediately after thoracic SMT in asymptomatic healthy subjects [34, 37] (Table 1). Seated or supine thoracic SMT to dysfunctional segments between T3-8 significantly increased bilateral lateral flexion when SMT was compared to the control group [37]. There was no significant difference in forward flexion or in lateral flexion when comparing SMT to the palpation group [37]. In the second study, SMT to T9 resulted in significant increased thoracic forward flexion compared to a sham procedure (SMT setup with no thrust), but no significant changes in thoracic extension, lumbar flexion or lumbar extension [34]. However, we did not calculate mean change and $95 \% \mathrm{CI}$ of this study.

Two studies examined the effect of cervical spine SMT on ROM [36, 39]. Bilateral cervicothoracic SMT significantly increased cervical ROM compared to an upper trapezius stretch and no intervention; however, differences varied based on the specific ROM (Table 1) (see Additional file 1) [39]. For all ranges except extension and right cervical rotation, there were significant differences between SMT and control groups [39]. For right lateral flexion, cervical flexion and left cervical rotation there were also significant differences between control and stretch groups [39]. For cervical extension, there was an increase in ROM when comparing SMT to stretch group and stretch to control group, but not between SMT and the control group [39]. For right cervical rotation, there were no significant changes [39]. In a study comparing cervical SMT based on joint dysfunction, to right sided C5 SMT and passive ROM groups, there were no significant changes in range of motion except for a significant increase in extension in both SMT groups compared to the passive ROM group and an increase in right lateral flexion with manipulation based on dysfunction compared to the passive ROM group [36].

Two studies investigated lumbopelvic SMT and ROM [42, 45] (Table 1). The first found that there was no significant effect of bilateral mid-lumbar SMT on the sit-and-reach test compared to a sham manipulation [42]. The second found that three weeks of weekly sacroiliac joint (SIJ) SMT, hip manipulation and a stretching program did not significantly increase hip extensibility, as measured with the modified Thomas Test, compared to a stretching program alone [45].

\section{Baropodometric and gait parameters}

Two studies examined the effect of SMT on baropodometry [14, 34] (Table 1). Mendez-Sanchez et al. [14] showed that bilateral SIJ SMT resulted in a significant change the weight variable $(\mathrm{kg})$ of both feet and the \% load of both hind feet compared to placebo technique of hip mobilization with no tension [14]. Ditcharles et al. [34] examined the effect of T9 SMT on gait initiating parameters [34]. They reported a significant decrease in all parameters measured, including anticipatory postural adjustments (APA) duration, peak of anticipatory backward center of pressure (COP) displacement, center of gravity (COG) velocity at toe-off (TO), mechanical efficiency of APA, peak of COG velocity, step length, and swing phase duration, immediately after SMT compared to controls (SMT setup with no thrust) [34]. 
Unfortunately, we did not calculate mean change and 95\% CI from this study.

\section{Other biomechanical outcomes}

Additional biomechanical outcomes reported in studies included lumbar spine proprioception, transversus abdominis (TA) thickness and scapular kinematics. Learman et al. [41] showed significant improvements in lumbar spine trunk joint position sense (JPS) in a randomized AB:BA crossover trial [41]. For the group that received SMT on the first session, JPS had an immediate significant improvement and a one-week residual effect [41]. In contrast, while the group that had a side-lying sham on the first session had a significant immediate improvement, there was no residual effect [41]. JPS was defined as the ability of a participant to reproduce trunk angle from neutral, after being passively brought to a position [41]. However, we did not measure mean change and 95\% CI from this study. Lumbar SMT had no significant effect on TA thickness measured with multiple ultrasound readings at rest or during contraction compared to a sham procedure [43]. TA thickness is used as an indicator of muscle activation [43]. Thoracic SMT did not have a significant immediate effect on scapular kinematics or scapulohumeral rhythm measured with 3D kinematics [44].

\section{Performance-based outcomes}

Two studies examined the immediate effect of a single session of SMT on sport-specific parameters but found no differences between groups [40, 42] (Table 1). Humphries et al. [40] found that left-sided C5-6 SMT had an immediate small significant effect on basketball free-throw accuracy compared to a sham procedure of $2.4 \%((95 \% \mathrm{CI}(0.656,4.14))[40]$. The sham procedure was an instrument-assisted intervention (Activator) set to provide zero force [40]. Olson et al. [42] found no significant effect of bilateral lumbar SMT on $0.5 \mathrm{~km}$ cycling sprint time compared to acupuncture and control groups within 15 min post intervention [42].

In addition, two studies assessed a course of weekly SMT on sport-specific parameters [32, 45]. Costa et al. [32] compared four weeks of weekly full spine SMT based on identified restriction and a standardized stretch program to the standardized stretch program alone on a golfing full-swing range [32]. There were no significant differences between groups [32]. Similarly, Sandell et al. [45] found that three weeks of weekly SIJ SMT, hip manipulation and stretching program had no significant effect on maximum running velocity over a $30 \mathrm{~m}$ distance after a $30 \mathrm{~m}$ running start, compared to a stretching program alone [45].

\section{Adverse events}

Four studies reported on adverse events [30, 36, 40, 44]. Of these, three studies reported no adverse events with any aspect of their protocol, including SMT [36, 40, 44]. Budgell and Polus [30] reported one subject in the sham group developed pain (increase in visual analogue scale (VAS) to 3.8/10) after the intervention, and two subjects in the SMT group developed pain (increase in VAS to 1.3 and 1.4/10) after the intervention [30].

\section{Discussion \\ Key findings}

The preponderance of evidence suggests that SMT in comparison to sham or other interventions does not significantly enhance performance-based outcomes as we defined. Several studies did report significant immediate effects of SMT in quadriceps and ankle plantarflexion MVC [31, 38], resting biceps brachii EMG [35], and trunk joint position sense [41]. It is unclear what impact these effects may have upon enhancing human performance over longer periods. However, there is one low risk of bias study suggesting that a single SMT improves basketball free throw accuracy immediately post intervention compared to sham $(2.4 \%, 0.66-4.14)$, which may be relevant in high-level sport performance [32]. Only two studies provided more than one SMT over a time [37, 42], neither which had a significant effect but broad CI suggest potential issue with sample size.

Other statistically significant changes were noted in ROM [34, 36, 37, 39] and baropodometric variables [14, 34]; however, the importance of such changes in uncertain. First, both these studies measured numerous ROM and additional outcomes and could be statistically significant based on chance alone. Second, in studies with a potentially minimally important change, the 95\% CI were wide, indicating imprecision of the outcome [36]. Conversely, in studies with narrow 95\% CI [37, 39], the noted significant changes may be of questionable relevant importance, especially in the cervical spine where results were less than reported measurement range of smallest detectable difference of $10-19^{\circ}$ [48].

Only four of 20 included studies reported adverse events. Of these studies, only minor adverse events were reported, which were associated with both SMT and sham procedures. These were described as increased pain after the intervention. The increases in VAS, particularly in the SMT group, may not be clinically significant, as the median VAS to denote a clinically important change in acute pain is 1.7 [49]. No further details on management of these adverse events were provided.

\section{Updating current literature}

The present systematic review provides an update to previous reviews by including articles investigating the effect of SMT in asymptomatic adult populations rather than athletes alone. The systematic review by Cerqueira et al. [11] examined the effect of HVLA SMT and 
athletic performance and found only five relevant studies [11]. Only two of these studies were included in our systematic review [40, 45], as two others were critically appraised but deemed to have a high risk of bias [50, 51], and one was not retrieved by our search strategy as the intervention was a HVLA thrust to the tibiotarsal joint, not the spine. Botelho et al. [12] conducted a similar systematic review and included seven relevant studies [12], four of which overlapped with Cerquira et al. [11] and four included in our systematic review. The three studies not included in our review were deemed to have a high risk of bias [50-52]. Both these recent reviews concluded that the current evidence is insufficient to determine if SMT should be used to improve athletic performance and future high quality research is required [11, 12].

Our systematic review suggests that SMT compared to sham or other interventions does not enhance performance-based outcomes as we defined, except in a few areas. The relevance to of such changes to improvement in functional or sport performance is unclear at this time. We agree with Cerqueira et al. [11] and Botelho et al. [12], that studies in this field require greater methodological rigor. Specifically, studies exploring athletic performance and the effect of SMT in asymptomatic adults should focus on identifying relevant and responsive outcome measures, use adequate sample sizes, include appropriate control groups, assess outcomes over longer temporal intervals, and explore the role of athlete expectations prior to intervention.

These recommendations are highlighted by various trends in this systematic review. Outcome measures varied widely across studies, often lacking reporting of measurement properties and appropriateness of these tools for the desired outcome. The longest time interval for the effect of SMT was one week by Learman et al. [41], which included a one week washout period in the crossover study [41]. Otherwise, the longest follow-up was $60 \mathrm{~min}$ after SMT [31, 38]. The rationale for SMT in each study varied, including SMT to identified joint dysfunction [31, 36], neurophysiological association of spinal segment and associated muscle groups [31, 38, 46], and SMT to T9 due to its classic definition as the "walking vertebra" [34]. This questions the validity and reliability of some theories, such as those historically based with limited scientific rationale or the reliability of identifying of spinal restrictions [53, 54]. Finally, 52 studies were eligible for full text appraisal; however, 32 were deemed to have a high risk of bias, indicating the overall poor methodological quality of this body of literature.

The vast majority of studies included in our review are exploratory in nature; they assess interventional efficacy, collect short-term outcomes, and can be used to design evaluation studies providing evidence for effectiveness [25]. We identified two studies that could be considered evaluation studies [32, 45]; however, when mean change and $95 \% \mathrm{CI}$ were measured, there was no effect of SMT on full-swing golfing range or running velocity, and a small mean change $\left(2.9^{\circ}-3.9^{\circ}\right)$ on hip extensibility [32, 45]. In addition, the included studies use different theories and outcomes that provides limited guidance in designing appropriate evaluation studies.

\section{Strengths and limitations}

Our systematic review has several strengths. These include a search strategy that was developed and checked through peer review and adapted for a broad set of databases to ensure identification of all possibly relevant articles. We also expanded our search terms to not only include athletes or sport performance, but to include studies that would have implications to athletes by including all asymptomatic adults. We used two independent reviewers for screening and critical appraisal to minimize error and bias and used a well-accepted and valid set of criteria (SIGN) for the critical appraisal of relevant studies.

This systematic review also has limitations. We did not perform a sensitivity analysis on thresholds for low risk of bias studies. The use of certain definitions in our research question was broad, such as performance-related outcomes, which may have made it difficult to identify relevant articles during the screening process, as evidenced by a large range of kappa-values. In addition, we may have missed studies that have secondary outcomes relevant to performance-outcomes that were not included in the title or abstract. We tried to mitigate such losses by hand searching relevant studies, but we did not search systematic reviews. We restricted our search to studies published in the English language, which may have excluded relevant studies. However, previous reviews have found that this has not led to biases in the reported results. [55]

\section{Conclusion}

In conclusion, the preponderance of evidence suggests that SMT compared to sham or other intervention does not enhance performance-related outcomes. Exceptions include exploratory evidence suggesting improvements in ankle plantarflexion and quadriceps MVC, resting biceps brachii EMG, lumbar joint position sense and basketball free throw accuracy. These findings are consistent with neurophysiological studies, wherein evidence suggests that SMT affects reflex responses at the spinal and cortical levels $[56,57]$. We found no conclusive explanatory evidence that SMT affects performance-related outcomes in the asymptomatic adult population. Further high-quality performance specific studies are required to confirm these preliminary findings.

\section{Additional files}

Additional file 1: Appendix I. Search strategy and search terms. (DOCX $15 \mathrm{~kb}$ ) 
Additional file 2: Appendix II. References for high risk of bias studies not included in this review. (DOCX $17 \mathrm{~kb}$ )

\section{Abbreviations}

APA: Anticipatory postural adjustments; COG: Center of gravity; COP: Center of pressure; EMG: Electromyography; HR: Heart rate; MEP: Maximal expiratory pressure; MIP: Maximal inspiratory pressure; MVC: Maximal voluntary contraction; RCT: Randomized controlled trial; ROM: Range of motion SIJ: Sacroiliac joint; SMT: Spinal manipulative therapy; TA: Transversus abdominis; TLC: Total lung capacity; TO: Toe-off

\section{Acknowledgements}

We are grateful to Drs. Jessica Wong and Genevieve Newton for their review and helpful suggested edits to our manuscript.

\section{Funding}

NA

\section{Availability of data and materials}

Available from corresponding author on reasonable request.

\section{Authors' contributions}

$\mathrm{MC}$ formulated and reviewed search terms and searches, distributed and organized articles for reviewers, screened and appraised articles, was the primary author of the manuscript, evidence tables and risk of bias Tables. SB, $\Pi$, SD, and SH screened and appraised articles, reviewed and edited the manuscript and evidence Tables. JS screened and appraised articles, reviewed and edited the manuscript, and advised throughout the review process. SM screened and appraised articles, reviewed and edited the manuscript and evidence tables, and advised throughout the review process. All authors read and approved the final manuscript.

\section{Ethics approval and consent to participate}

NA

\section{Consent for publication}

NA

\section{Competing interests}

This article was commissioned and peer reviewed.

\section{Publisher's Note}

Springer Nature remains neutral with regard to jurisdictional claims in published maps and institutional affiliations.

\section{Author details}

${ }^{1}$ Canadian Memorial Chiropractic College, 6100 Leslie Street, North York, ON M2H 3J1, Canada. ${ }^{2}$ University of Guelph, Guelph, ON, Canada.

Received: 26 November 2018 Accepted: 26 March 2019

Published online: 07 June 2019

\section{References}

1. Miners AL, Degraauw C. A survey of fellows in the College of Chiropractic Sports Sciences (Canada): their intervention practices and intended therapeutic outcomes when treating athletes. J Can Chiropr Assoc. 2010; 54(4):282-92.

2. Adams J, Lauche R, de Luca K, Swain M, Peng W, Sibbritt D. Prevalence and profile of Australian chiropractors treating athletes or sports people: a crosssectional study. Complement Ther Med. 2018;39:56-61. https://doi.org/10. 1016/j.ctim.2018.05.003

3. Hurwitz EL. Epidemiology: spinal manipulation utilization. J Electromyogr Kinesiol. 2012;22(5):648-54

4. Stump JL, Redwood D. The use and role of sport chiropractors in the national football league: a short report. J Manip Physiol Ther. 2002;25(3):E2

5. Minkalis AL, Vining RD, Long CR, Hawk C, de Luca K. A systematic review of thrust manipulation for non-surgical shoulder conditions. Chiropr Man Therap. 2017;25(1):1

6. Southerst D, Yu H, Randhawa K, Côté P, D'Angelo K, Shearer HM, et al. The effectiveness of manual therapy for the management of musculoskeletal disorders of the upper and lower extremities: a systematic review by the Ontario protocol for traffic injury management (OPTIMa) collaboration. Chiropr Man Therap. 2015;23(1):30.

7. Bronfort G, Haas M, Evans RL, Bouter LM. Efficacy of spinal manipulation and mobilization for low back pain and neck pain: a systematic review and best evidence synthesis. Spine J. 2004:4(3):335-56.

8. Olympic Games. 2016 [cited 2018 Jul 20]. Available from: https://www olympic.org/rio-2016/athletics/100m-men

9. Nook DD, Nook EC, Nook BC. Utilization of chiropractic Care at the World Games 2013. J Manip Physiol Ther. 2016;39(9):693-704.

10. Miners AL. Chiropractic treatment and the enhancement of sport performance: a narrative literature review. J Can Chiropr Assoc. 2010;54(4):210-21.

11. Cerqueira MS, Sales RM. High-velocity low-amplitude manipulation ( thrust ) and athletic performance : a systematic review. Fisioterapia em Movimento. 2017;30:413-22.

12. Botelho MB, Alvarenga BAP, Molina N, Ribas M, Baptista AF. Spinal manipulative therapy and sports performance enhancement: a systematic review. J Manip Physiol Ther. 2017;40(7):535-43.

13. Pollard H, Ward G. Strength change of quadriceps femoris following a single manipulation of the L3/4 vertebral motion segment: a preliminary investigation. J Neuromusculoskel Syst. 1996:4(4):137-44.

14. Méndez-Sánchez R, González-Iglesias J, Sánchez-Sánchez JL, PuenteGonzález AS. Immediate effects of bilateral sacroiliac joint manipulation on plantar pressure distribution in asymptomatic participants. J Altern Complement Med. 2014;20(4):251-7.

15. McGowan JS, Lefebvre C. An evidence based checklist for the peer review of electronic search strategies (PRESS EBC). 2010;

16. Sampson M, McGowan J, Cogo E, Grimshaw J, Moher D, Lefebvre C. An evidence-based practice guideline for the peer review of electronic search strategies. J Clin Epidemiol. 2009:62(9):944-52.

17. Eldridge SM, Lancaster GA, Campbell MJ, Thabane L, Hopewell S, Coleman $\mathrm{CL}$, et al. Defining feasibility and pilot studies in preparation for randomised controlled trials: development of a conceptual framework. PLoS One. 2016; 11(3):1-22.

18. Herzog W. The biomechanics of spinal manipulation. J Bodyw Mov Ther. 2010;14(3):280-6.

19. Baechle T, Earle R. Essentials of strength and conditioning. 3rd ed. Windsor: Human Kinetics; 2008

20. Aruin AS. Biomechanics. Encyclopaedia Britannica. 2016 [cited 2018 Jul 14] Available from: https:/www britannica com/science/biomechanics-science

21. Scheer BT. Physiology. Encyclopaedia Britannica. [cited 2018 Jul 14]. Available from: https://www.britannica.com/science/physiology

22. Merriam-Webster Dictionary: Medical Dictionary. 2016.

23. Harbour R, Miller K. A new system for grading recommendations in evidence based guidelines. Br Med J (Clinical Res Ed). 2001;323(7308):334-6.

24. Scottish Intercollegiate Guidelines Network Critical appraisal: notes and checklists. 2013. Available from: https://www.sign.ac.uk/checklists-and-notes.html.

25. Wong JJ, Shearer HM, Mior S, Jacobs C, Côté P, Randhawa K, et al. Are manual therapies, passive physical modalities, or acupuncture effective for the management of patients with whiplash-associated disorders or neck pain and associated disorders? An update of the bone and joint decade task force on neck pain and its ass. Spine J. 2016;16:1598-630 p. Available from. https://doi.org/10.1016/j.spinee.2015.08.024.

26. Slavin R. Best evidence synthesis: an intelligent alternative to meta-analysis. J Clin Epidemiol. 1995:48:9-18.

27. Viera A, Garrett J. Understanding interobserver agreement: the kappa statistic. Fam Med. 2005:37:360-3.

28. McHugh ML. Interrater reliability: the kappa statistic. Biochem Medica. 2012; 22(3):276-82.

29. Moher D, Liberati A, Tetzlaff J, Altman D. Preferred reporting items for 5 systematic reviews and meta-analyses: the PRISMA statement. Br Med J. 2009;339:b2535.

30. Budgell $B$, Polus $B$. The effects of thoracic manipulation on heart rate variability: a controlled crossover trial. J Manip Physiol Ther. 2006;29(8):603-10.

31. Christiansen TL, Niazi IK, Holt K, Nedergaard RW, Duehr J, Allen K, et al. The effects of a single session of spinal manipulation on strength and cortical drive in athletes. Eur J Appl Physiol. 2018;118(4):737-49.

32. Costa SMV Chibana YET, Giavarotti L, Compagnoni DS, Shiono AH, Satie J, et al. Effect of spinal manipulative therapy with stretching compared with stretching alone on full-swing performance of golf players: a randomized pilot trial. J Chiropr Med. 2009;8(4):165-70. 
33. Da Silva PHL, De Ré D, Behne GR, Vazatta MP, De Carvalho AR. Maximum respiratory pressure alterations after spinal manipulation. Eur J Phys. 2013; 15(2):64-9.

34. Ditcharles S, Yiou E, Delafontaine A, Hamaoui A. Short-term effects of thoracic spine manipulation on the biomechanical organisation of gait initiation: a randomized pilot study. Front Hum Neurosci. 2017:11:1-11.

35. Dunning J, Rushton A. The effects of cervical high-velocity low-amplitude thrust manipulation on resting electromyographic activity of the biceps brachii muscle. Man Ther. 2009;14(5):508-13.

36. Galindez-Ibarbengoetxea X, Setuain I, González-Izal M, Jauregi A, RamírezVelez R, Andersen LL, et al. Randomised controlled pilot trial of highvelocity, low-amplitude manipulation on cervical and upper thoracic spine levels in asymptomatic subjects. Int J Osteopath Med. 2017;25:6-14.

37. Gavin D. The effect of joint manipulation techniques on active range of motion in the mid-thoracic spine of asymptomatic sybjects. J Man Manip Ther. 1999;7(3):114-22.

38. Grindstaff TL, Hertel J, Beazell JR, Magrum EM, Ingersoll CD. Effects of lumbopelvic joint manipulation on quadriceps activation and strength in healthy individuals. Man Ther. 2009;14(4):415-20.

39. Hanney WJ, Puentedura EJ, Kolber MJ, Liu X, Pabian PS, Cheatham SW. The immediate effects of manual stretching and cervicothoracic junction manipulation on cervical range of motion and upper trapezius pressure pain thresholds. J Back Musculoskelet Rehabil. 2017;30(5):1005-13.

40. Humphries KM, Ward J, Coats J, Nobert J, Amonette W, Dyess S. Immediate effects of lower cervical spine manipulation on handgrip strength and freethrow accuracy of asymptomatic basketball players: a pilot study. J Chiropr Med. 2013 Sep;12(3):153-9.

41. Learman KE, Myers JB, Lephart SM, Sell TC, Kerns GJ, Cook CE. Effects of spina manipulation on trunk proprioception in subjects with chronic low Back pain during symptom remission. J Manip Physiol Ther. 2009;32(2):118-26.

42. Olson E, Bodziony M, Ward J, Coats J, Koby B, Goehry D. Effect of lumbar spine manipulation on asymptomatic cyclist sprint performance and hip flexibility. J Chiropr Med. 2014;13(4):230-8

43. Puentedura EJ, Landers MR, Hurt K, Meissner M, Mills J, Young D. Immediate effects of lumbar spine manipulation on the resting and contraction thickness of transversus abdominis in asymptomatic individuals. J Orthop Sports Phys Ther. 2011;41(1):13-21.

44. Rosa DP, Alburquerque-Sendín F, Salvini TF, Camargo PR. Effect of seated thoracic manipulation on changes in scapular kinematics and scapulohumeral rhythm in young asymptomatic participants: a randomized study. J Manip Physiol Ther. 2013 Oct;36(8):546-54.

45. Sandell J, Palmgren PJ, Björndahl L. Effect of chiropractic treatment on hip extension ability and running velocity among young male running athletes. J Chiropr Med. 2008;7(2):39-47.

46. Sanders GD, Nitz AJ, Abel MG, Symons TB, Shapiro R, Black WS, et al. Effects of lumbosacral manipulation on isokinetic strength of the knee extensors and flexors in healthy subjects: a randomized, controlled, single-blind crossover trial. J Chiropr Med. 2015 Dec;14(4):240-8.

47. Ward J. Lumbar spine manipulation impact on exercise science measures. J Am Chiropr Assoc. 2013:21-34.

48. Mangone M, Bernetti A, Germanotta M, Sipio D, Razzano C, loppolo F, et al. Reliability of the cervical spine device for the assessment of cervical spine range of motion in asymptomatic participants. J Manipulative Physiol Ther. 41(4):342-9. Available from: https://doi.org/10.1016/j.jmpt.2018.01.003.

49. Olsen MF, Bjerre E, Hansen MD, Hilden J, Landler NE, Tendal B, et al. Pain relief that matters to patients: systematic review of empirical studies assessing the minimum clinically important difference in acute pain. BMC Med. 2017;15(1):1-18.

50. Shrier I, Macdonald D, Uchacz G. A pilot study on the effects of pre-event manipulation on jump height and running velocity. Br J Sports Med. 2006; 40:947-9.

51. Botelho MB, Andrade BB. Effect of cervical spine manipulative therapy on judo athletes' grip strength. J Manip Physiol Ther. 2012;35(1):38-44.

52. Deutschmann $K$, Jones A, Korporaal C. A non-randomised experimental feasibility study into the immediate effect of three different spinal manipulative protocols on kicking speed performance in soccer players. Chiropr Man Therap. 2015;23(1):1

53. Potter L, McCarthy C, Oldham J. Intraexaminer reliability of identifying a dysfunctional segment in the thoracic and lumbar spine. J Manip Physiol Ther. 2006;29(3):203-7.
54. Heiderscheit BBW. Reliability of joint mobility and pain assessment of the thoracic spine and rib cage in asymptomatic individuals. J Man Manip Ther. 2008;16(4):210-6.

55. Johnson AP, Sikich NJ, Evans G, Evans W, Giacomini M, Glendining M, et al. Health technology assessment: a comprehensive framework for evidencebased recommendations in Ontario. Int J Technol Assess Health Care. 2009; 25(2):141-50.

56. Pickar JG. Neurophysiological effects of spinal manipulation. Spine J. 2002; 2(5):357-71.

57. Haavik H, Murphy B. The role of spinal manipulation in addressing disordered sensorimotor integration and altered motor control. J Electromyogr Kinesiol. 2012;22(5):768-76.
Ready to submit your research? Choose BMC and benefit from:

- fast, convenient online submission

- thorough peer review by experienced researchers in your field

- rapid publication on acceptance

- support for research data, including large and complex data types

- gold Open Access which fosters wider collaboration and increased citations

- maximum visibility for your research: over $100 \mathrm{M}$ website views per year

At $\mathrm{BMC}$, research is always in progress.

Learn more biomedcentral.com/submissions 